Brit. J. industr. Med., 1955, 12, 131.

\title{
INVESTIGATIONS INTO THE EFFECTS OF EXPOSURE TO TRICHLORETHYLENE IN MECHANICAL ENGINEERING*†
}

\author{
BY
}

\author{
E. GRANDJEAN, R. MÜNCHINGER, V. TURRIAN, P. A. HAAS, \\ H.-K. KNOEPFEL, and H. ROSENMUND
}

\begin{abstract}
From the Institute of Hygiene and of Industrial Physiology of the Swiss Federal Institute of Technology, Zurich, the Institute of Aviation Medicine, Dübendorf, and the Laboratory of Medical Chemistry of the Cantonal Hospital of Zurich
\end{abstract}

(RECEIVED FOR PUBLICATION SEPTEMBER 28, 1954)

Trichlorethylene (tri) is a solvent widely used in mechanical engineering, where it is employed mainly for cleansing and degreasing. Its main advantages are that it is non-inflammable; is an excellent degreasing agent, and is relatively inexpensive.

Although tri was for a long time considered to be only very mildly toxic, there has been, in recent years, a great increase in research and investigation into its toxic effects. Severe poisoning is characterized by a narcotic action which, if exposure is sufficiently prolonged, may lead to death. Chronic inhalation, continued over a period of years, seems mainly to attack the nervous system, the symptoms most frequently met with being giddiness, headaches, insomnia, tiredness, troubles of the vegetative nervous system, neuritis, and inability to tolerate alcohol.

The maximum allowable concentration (m.a.c.) has been fixed by various institutions and authors as follows :-

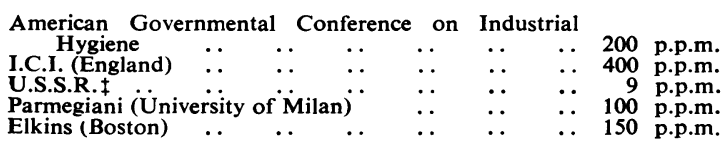

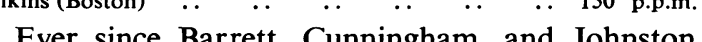

1939) found that some of the tri is eliminated in the urine in the form of trichloracetic acid, several writers have set out to analyse the urine of workers and to take the quantity of trichloracetic (T.C.A.) acid found as the criterion of exposure. Ahlmark and

*This work has been made possible by the generosity of the National Foundation for the Development of Swiss National Economy through Scientific Research.

This paper was submitted in French and has been translated.

$¥$ According to a circular letter by Ahlmark (Sweden) and an article published by Bardoděj, Berka, Chalupa, Nesvadba, and Vyskočil (1952).
Forssman (1951a) examined 122 workers dealing with tri and found subjective disturbances in $50 \%$ of these men who were eliminating between 40 and $75 \mathrm{mg}$. of trichloracetic acid per litre of urine. In almost all cases where elimination exceeded $100 \mathrm{mg}$. per litre disturbances were present. These writers concluded that an elimination of up to $20 \mathrm{mg}$. of trichloracetic acid per litre of urine could be tolerated.

In view of the fact that until now there has been no systematic investigation into exposure to tri in the mechanical engineering industry, we considered that such a study would be useful. We decided to proceed by determining the concentration of tri in the air in workshops and by measuring the elimination of trichloracetic acid by workers, at the same time inquiring into their general state of health.

Method
Analysis of the Air.-We collected tri vapours in ethylic alcohol $95 \%$ by passing the air to be successively analysed through two washing bottles (impingers). The volume of air passing through the washing bottles was checked and determined by means of a flowmeter.

The tri absorbed was then quantitatively measured according to the method of Truhaut (1951), which we modified slightly. This method is based on a coloured reaction between the tri and the pyridin in an alkaline medium (Fujiwara's reaction). Our modifications of Truhaut's method were as follows :

To $1 \mathrm{ml}$. of the alcohol solution of tri we added $3 \mathrm{ml}$. of pyridin (purified) and $1 \mathrm{ml}$. of $1 \% \mathrm{NaOH}$ in alcohol. After shaking, the solution was heated for five minutes in a water-bath at $65^{\circ} \mathrm{C}$. A violet-red colour developed uniformly throughout the solution. When it cooled, $2 \mathrm{ml}$. of distilled water was added, and after two minutes the intensity of the colour was measured with a Beckman's spectrophotometer and the extinction determined 
at a wavelength of $550 \mu$ (or $5500 \AA$.). We prepared a graph for every series of analyses.

Analysis of Trichloracetic Acid in the Urine.-Ahlmark and Forssman (1951a) found that there was only a very slight variation in the elimination of T.C.A. in the course of the day. During our preliminary experiments, we ourselves noted that the quantities of T.C.A. varied only slightly from day to day for the same worker. We therefore confined ourselves to examining samples of urine taken at any hour of the day.

The quantitative analysis of the T.C.A. was carried out according to Fabre's (1949) method which we modified slightly. After treating with tungstate according to Fabre's directions, to $1 \mathrm{ml}$. of filtrate we added $3 \mathrm{ml}$. of pyridin and $1 \mathrm{ml}$. of $\mathrm{N} . \mathrm{NaOH}$ (purified). The next steps were identical with those described above for the quantitative analysis of tri in the air. It should te noted that we had to prepare a separate graph for every specimen of urine in respect of its colorimetric analysis.

Clinical Examination.-Every worker underwent a detailed clinical examination, which included occupational and personal histories, physical examination of the respiratory and circulatory organs, liver, etc., neurological examination of pupillary reflexes, of cutaneous and deep sensitivity, of cutaneous and proprioceptive reflexes, of hearing and of sight, psychiatric examination, especially in respect of fixation memory, attention, comprehension, ideation, and affectivity.

For this purpose we carried out a clinico-psychiatric examination together with the tests of Meggendorf, Bourdon, Rorschach, and Jung, Knoepfel's (1952) "thirteen mistakes" test, and Bleuler's (1943) "ass laden with salt" test. These tests, in conjunction with the psychiatric examination, are likely to reveal a group of symptoms which, following Bleuler (1954), we call the psycho-organic syndrome. This syndrome is mainly characterized by a diminution of memory, a reduction of the power of reflexion and understanding, and by changes in affective powers. It is found in a more or less acute form in patients suffering from a chronic, diffuse lesion of the brain and more especially after serious trauma to the brain, in cerebral arteriosclerosis, and in many cases of poisoning by lead or mercury, or by organic solvents.

A blood examination, including a count of red corpuscles, a determination of the haemoglobin, and the sedimentation rate, and a differential white cell count, was made.

We also carried out biochemical tests to determine non-protein nitrogen, plasma protein, serum bilirubin, blood cholesterol, serum iron and alkaline phosphatase, the Takata-Ara reaction, the Hangar reaction, the Weltmann test, the cadmium reaction, the Quick test, and the blood calcium.

An analysis of urine, including an examination for albumin, sugar, and urobilinogen, was made.

We examined in all 80 workers, seven of whom stopped working with tri from three weeks to six years before. Twenty-three of the workers were not clinically examined and in these we confined ourselves to a case history of subjective troubles and an analysis of trichloracetic acid in the urine. These 80 workers were employed in 24 workshops belonging to 10 different factories of the Swiss mechanical engineering industry.

In all these factories tri is used in degreasing equipment. This usually consists of tanks in which quantities of solvent, varying from a few litres to a few hundred litres,

TABLE 1

AVERAGE CONCENTRATION OF TRI IN THE AIR OF THE WORKSHOPS

\begin{tabular}{|c|c|c|c|c|c|c|c|c|}
\hline \multirow{2}{*}{\multicolumn{3}{|c|}{ Workshop }} & \multicolumn{3}{|c|}{ Near the Tank } & \multicolumn{3}{|c|}{ Centre of the Workshop } \\
\hline & & & $\begin{array}{l}\text { No. of } \\
\text { Analyses }\end{array}$ & $\begin{array}{c}\text { Extreme } \\
\text { Range }\end{array}$ & Averages & $\begin{array}{l}\text { No. of } \\
\text { Analyses }\end{array}$ & $\begin{array}{c}\text { Extreme } \\
\text { Range }\end{array}$ & Averages \\
\hline $\begin{array}{r}\text { Open Tanks } \\
\text { II } \\
\text { II } \\
\text { III } \\
\text { IV } \\
\text { VI } \\
\text { VII } \\
\text { XI } \\
\text { XII } \\
\text { XV } \\
\text { XVI } \\
\text { XVIII } \\
\text { XXII } \\
\text { XXIII } \\
\text { XXIV } \\
\end{array}$ & $\begin{array}{l}\because \\
\cdots \\
\cdots \\
\cdots \\
\cdots \\
\cdots \\
\therefore \\
\cdots \\
\cdots\end{array}$ & 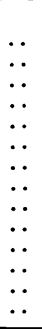 & $\begin{array}{l}8 \\
4 \\
5 \\
5 \\
1 \\
5 \\
2 \\
4 \\
2 \\
2 \\
7 \\
3 \\
1 \\
1\end{array}$ & $\begin{array}{c}6-84 \\
17-23 \\
27-60 \\
1-8 \\
325 \\
85-198 \\
57-68 \\
29-51 \\
45 \\
30-35 \\
27-46 \\
18-27 \\
25 \\
20 \\
\end{array}$ & $\begin{array}{c}30 \cdot 5 \\
21 \cdot 8 \\
35 \cdot 6 \\
5 \\
325 \\
131 \cdot 4 \\
62 \cdot 5 \\
40 \cdot 3 \\
45 \\
32 \cdot 5 \\
33 \cdot 5 \\
22 \cdot 3 \\
25 \\
20\end{array}$ & $\begin{array}{l}8 \\
2 \\
4 \\
1 \\
3 \\
1 \\
= \\
= \\
2 \\
1 \\
1 \\
\end{array}$ & $\begin{array}{c}15-63 \\
8-10 \\
13-18 \\
2 \\
127-335 \\
133 \\
= \\
= \\
25-27 \\
27 \\
10 \\
-\end{array}$ & $\begin{array}{c}37 \cdot 6 \\
9 \\
15 \\
2 \\
225 \\
133 \\
= \\
= \\
\overline{26} \\
27 \\
10 \\
\end{array}$ \\
\hline \multicolumn{2}{|c|}{ Averages.. } & $\cdots$ & - & - & $59 \cdot 5$ & 一 & 一 & $53 \cdot 8$ \\
\hline $\begin{array}{r}\text { Closed Tanks } \\
\text { V } \\
\text { VIII } \\
\text { IX } \\
\mathbf{X} \\
\text { XIII } \\
\text { XIV }\end{array}$ & $\begin{array}{l}\ddot{ } \\
\ddot{*} \\
\ddot{*} \\
\ddot{*}\end{array}$ & $\begin{array}{l}\ddot{*} \\
\ddot{*} \\
\ddot{*}\end{array}$ & $\begin{array}{l}2 \\
1 \\
1 \\
1 \\
2 \\
3\end{array}$ & $\begin{array}{l}13-56 \\
11 \\
13 \\
35 \\
23-40 \\
18-20\end{array}$ & $\begin{array}{l}34 \cdot 5 \\
11 \\
13 \\
35 \\
31 \cdot 5 \\
19 \\
\end{array}$ & $\frac{\overline{ }}{1}$ & $\begin{array}{l}\text { E } \\
35 \\
-\end{array}$ & $\frac{二}{35}$ \\
\hline \multicolumn{2}{|c|}{ Averages.. } & .. & 一 & 一 & 24 & 一 & - & 一 \\
\hline
\end{tabular}

(p.p.m. = parts per million $=\mathrm{ml}$. of vapour/cu.m. of air) 
are heated to 70 or $80^{\circ} \mathrm{C}$. Generally speaking, there are two kinds of tanks in these factories: (1) open tanks, in which the worker dips the parts to be cleaned in the solvent, and (2) closed tanks, where the dipping is done automatically without any interference by the worker during the degreasing process. All the open tanks were equipped with refrigerator coils to condense the tri vapours, together with an air exhaust system at the side of the tank. A similar installation was included in the closed tanks in order to get rid of the tri vapours.

\section{Results}

Concentration of Tri in the Air in Workshops.Specimens of air for chemical analysis were taken at a height of $160 \mathrm{~cm}$., that is to say, above the edge of open tanks or in the immediate proximity of the loading apertures of closed tanks, or again at a few metres' distance from the tanks, generally speaking, in the centre of the workshops near where the loading and unloading of dipping containers took place. The taking of air samples lasted from five to 10 minutes and workers were requested to work as usual during this time. Thus the number of dippings varied from one sampling to the next.

In the 20 workshops we made in all 84 analyses of air, 60 close to the tanks and 24 in the centre of the workshop (Table 1).

In most cases concentrations of tri near the tanks varied from 20 to 40 p.p.m. If we compare the amounts obtained near open tanks with those obtained near closed tanks we notice a difference in favour of the latter. The amounts obtained in the centre of the workshops were very similar to the amounts obtained close to the tanks.

In workshops VI and VII we noticed that the men worked without taking precautions, allowing parts to drip outside the tanks and occasionally using tri outside the tank.

In two workshops we took two sets of readings at different times of the day in order to test the effect of a variation in the conditions in which the experiments were made. The amounts shown in these two sets of readings are set out in Table 2.

In workshop I concentration varied during the morning between 6 and 53 p.p.m., while in workshop XVIII it varied between 25 and 40 p.p.m. According to our observers on the spot, these variations in concentration should be attributed mainly to local conditions of ventilation at the time of the analysis ; other factors, such as the length of time parts were allowed to dry within the tank and the shape of the parts dipped, also played an important part.

Twice we came across open tanks where degreasing was going on at the vapour stage. The readings we took close to these tanks showed
TABLE 2

VARIATIONS IN THE CONCENTRATION OF TRI IN THE AIR

\begin{tabular}{|c|c|c|c|c|c|}
\hline Time & \multicolumn{3}{|c|}{ Place of Analysis } & Kind of Work & p.p.m. \\
\hline 9.30 & \multicolumn{3}{|c|}{ Workshop I, centre of } & Drying a basket & 15 \\
\hline 9.40 & ," & " & $\begin{array}{l}\text { near the } \\
\text { open tank }\end{array}$ & $\begin{array}{c}\text { Dipping and drying a } \\
\text { basket }\end{array}$ & 6 \\
\hline 10.00 & ", & " & centre of & Unloading a basket & 15 \\
\hline 10.10 & $"$ & & $\begin{array}{l}\text { near the } \\
\text { open tank }\end{array}$ & Dipping a single part & 10 \\
\hline $\begin{array}{l}10.25 \\
10.35\end{array}$ & ," & ", & $"$ & Withdrawal of part and & 8 \\
\hline 10.59 & " & " & $\begin{array}{l}\text { centre of } \\
\text { workshop }\end{array}$ & $\begin{array}{l}\text { drying } \\
\text { Dipping and drying a } \\
\text { basket }\end{array}$ & 30 \\
\hline 11.10 & , & & $\begin{array}{l}\text { near the } \\
\text { open tank }\end{array}$ & ", & 53 \\
\hline 11.20 & $"$ & & $\begin{array}{l}\text { centre of } \\
\text { workshop }\end{array}$ & $\begin{array}{l}\text { Drying a basket and of } \\
\text { large parts }\end{array}$ & 39 \\
\hline 11.30 & $"$ & " & $\begin{array}{l}\text { near the } \\
\text { open tank }\end{array}$ & $\begin{array}{l}\text { Dipping and drying a } \\
\text { basket }\end{array}$ & 31 \\
\hline 11.45 & , & " & $\begin{array}{l}\text { centre of } \\
\text { workshop }\end{array}$ & $\begin{array}{c}\text { Drying a basket and } \\
\text { washing an apron }\end{array}$ & 32 \\
\hline 9.15 & " & XVII & $\begin{array}{l}\text { I, near the } \\
\text { open tank }\end{array}$ & $\underset{\text { tri }}{\text { Filling the tark with }}$ & 40 \\
\hline 9.25 & , & , & ", & $\begin{array}{l}\text { Drying a basket and } \\
\text { hand cleaning of } \\
\text { various parts }\end{array}$ & 27 \\
\hline 10.10 & , & ", & " & $\begin{array}{l}\text { Dipping and drying } 3 \\
\text { baskets }\end{array}$ & 29 \\
\hline 10.25 & " & , & , & $\begin{array}{l}\text { Dipping and drying } 4 \\
\text { baskets }\end{array}$ & 34 \\
\hline 10.40 & ", & ” & $\begin{array}{l}\text { centre of } \\
\text { workshop }\end{array}$ & 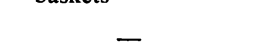 & 25 \\
\hline 10.50 & , & , & $\begin{array}{l}\text { near the } \\
\text { open tank }\end{array}$ & $\begin{array}{l}\text { Dipping and drying } 5 \\
\text { baskets }\end{array}$ & 29 \\
\hline
\end{tabular}

amounts similar to those found at open tanks, namely an average concentration of 37 p.p.m. on five readings, with extreme limits of 8 and 63 p.p.m.

On two occasions we noticed workmen using cold tri in vats wholly lacking in safety devices or any ventilation system. Concentration of tri in the air during this work varied from 67 to 157 p.p.m., the average amount being 105 p.p.m.

We also determined the concentration of tri in the air of the workshops in relation to the length of

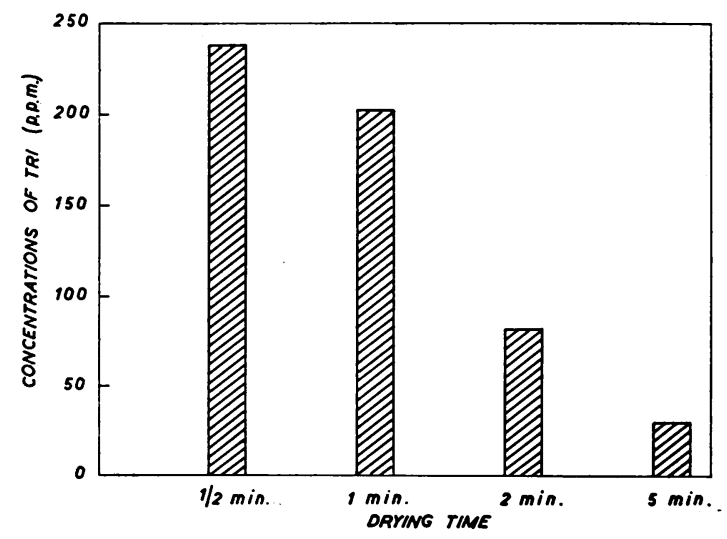

FIG. 1.-Concentration of trichlorethylene in the air in relation to drying time of parts inside apparatus. 


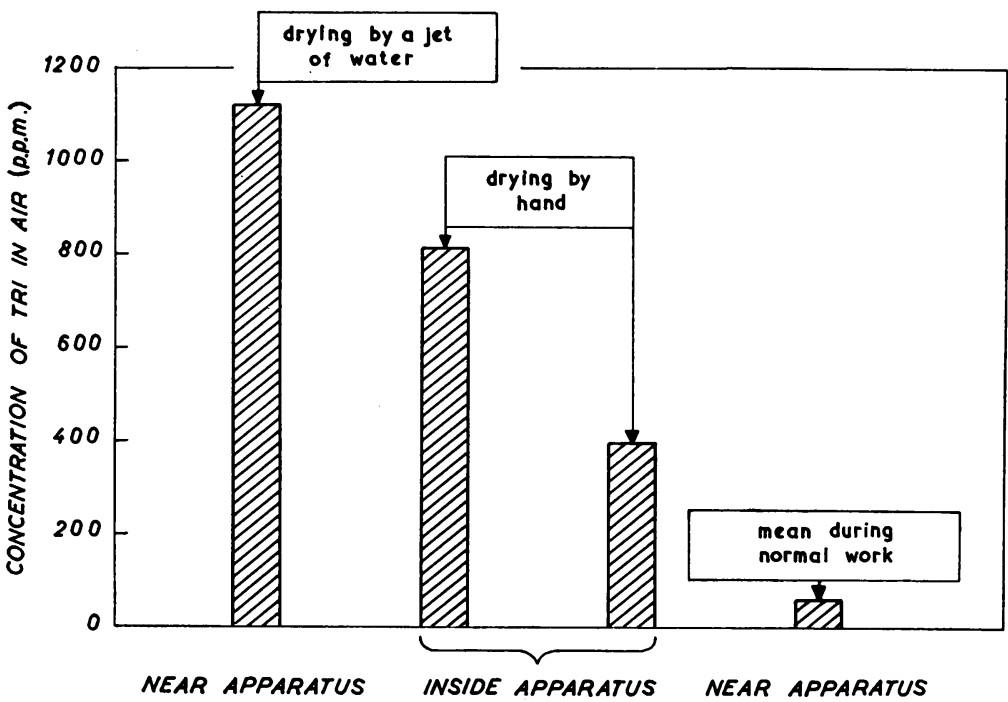

Fig. 2.-Concentration of trichlorethylene in the air during the cleaning of the apparatus.
(The relatively high amounts, 112 and 167 p.p.m., found in this set of experiments were partly due to the presence of large-scale suction pumps in paint-spraying sheds close by.)

Elimination of T.C.A. by Workmen Using Tri.-In a preliminary experiment we studied the elimination of trichloracetic acid in the urine for four consecutive days by 11 workmen regularly using tri. The total amount of urine passed in 24 hours was collected and submitted to chemical analysis. Both the individual amounts and the average amounts for each workman are seen in Table 3.

TABLE 3

time parts were left to drip and dry inside the tank. The results of this experiment are shown in Fig. 1. We found that the concentration of tri in the air was considerably reduced when drying time inside the apparatus was prolonged from half a minute to five minutes.

Tri equipment is cleaned once or twice a week. We examined the concentration of tri near the tank during one cleaning operation. In the case in question, the workman emptied the tank, rinsed it with water from a powerful hose pipe, then got inside the tank and spent half an hour cleaning with a scrubbing brush. Analyses of the air showed a concentration of 1,120 p.p.m. outside the tank while the hose pipe was in action, with 815 and 395 p.p.m. inside the apparatus during and after the scrubbing respectively (Fig. 2).

We also made air analyses using various methods of ventilation while work was being carried on normally. The workshop under consideration was fitted with a mixed system of mechanical ventilation including both air suction and air blowing. On the upper edge of the tri tank was fixed a lateral suction pump which was intended to get rid of the rising tri vapour. The results were as follows :

\begin{tabular}{|c|c|}
\hline Kind of Ventilation & $\begin{array}{c}\text { Average Concentration of } \\
\text { Tri in Air (p.p.m.) }\end{array}$ \\
\hline $\begin{array}{l}\text { No ventilation } \ldots \\
\text { Lateral suction pump at the level of } \\
\text { tri tank } \\
\text { General ventilation and local suction } \\
\text { pump }\end{array}$ & $\begin{array}{r}167 \\
112 \\
53\end{array}$ \\
\hline
\end{tabular}


of tri in the air. By means of analyses of air, we were able to determine the concentrations of tri to which 55 of these workmen were frequently exposed. It was not possible to determine with sufficient accuracy the degree of concentration to which the other workmen were exposed. The results, which are set out in Fig. 3, show that in respect of our 55 workmen there could hardly be said to be any definite relation between the two sets of readings.

We noted that men working all day with tri showed on an average larger amounts of T.C.A. than those who worked only part of the time at the tri tanks. This led us to calculate in the case of

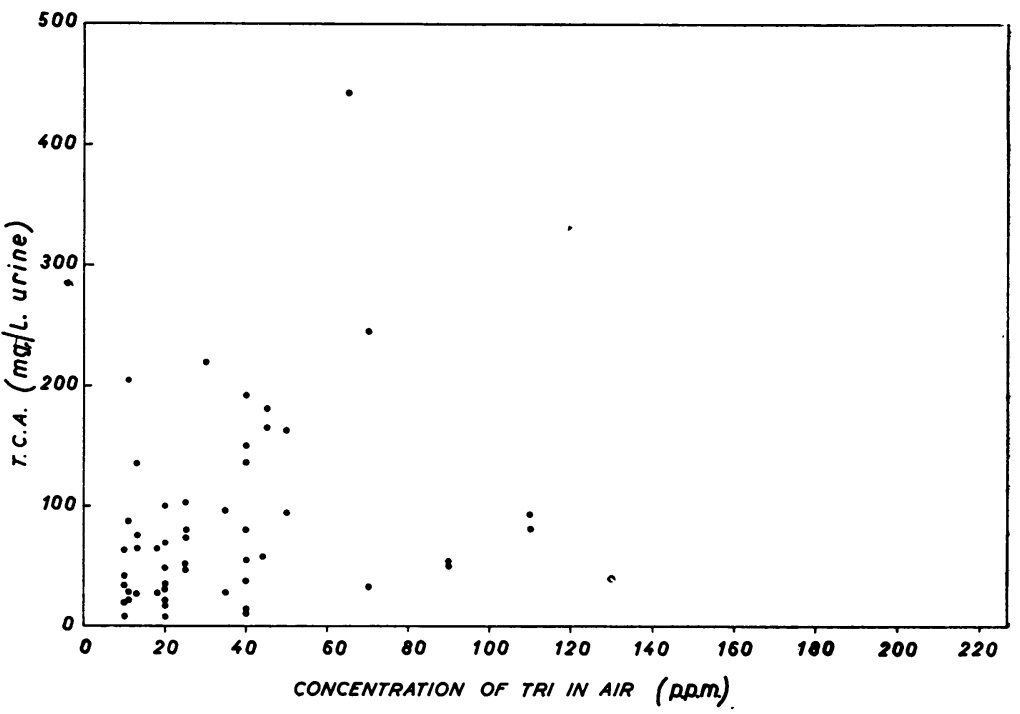

FIG. 3.-Elimination of trichloracetic acid and concentration of trichlorethylene in the air of workshops. 52 workmen the product of tri (p.p.m.) in the atmosphere $\times$ the length of time spent working with tri. (We lacked sufficiently accurate bases on which to make this calculation in the other cases.) In our calculations, the length of time spent working with tri was expressed as a percentage of the total of working hours. In the case of a workman spending one-third of his time in contact with tri and exposed to a concentration of 60 p.p.m., for example, we would obtain a product of $0.33 \times$ $60=20$. Fig. 4 shows the elimination of T.C.A. in relation to the product of the p.p.m. concentration and the length of exposure to tri ; this product we shall henceforth call the theoretical exposure. This graph shows that there is a certain relation between the elimination of T.C.A. and the theoretical exposure. Calculations have given a coefficient of correlation $r=+0.68$ and a coefficient of determination $B=0.46$. This means that $46 \%$ of the variations in T.C.A. may be attributed to corresponding variations in the theoretical exposure. The coefficient of regression amounted to $b=2.99$. We may thus conclude that, on an average, the relation of T.C.A. to theoretical exposure is $3: 1$.

Twenty-five of our workmen spent the entire day at the tri tanks. When we compared their actual exposure with their elimination of T.C.A., we obtained the following average amounts :

\begin{tabular}{c|c|c}
\hline $\begin{array}{c}\text { Number of Workmen } \\
\text { Spending 8 Hours/Day } \\
\text { at Tri Tanks }\end{array}$ & $\begin{array}{c}\text { Average } \\
\text { Elimination } \\
\text { (mg./1.) }\end{array}$ & $\begin{array}{c}\text { Average } \\
\text { Exposure } \\
\text { (p.p.m.) }\end{array}$ \\
\hline 25 & 86.2 & 24.9 \\
\hline
\end{tabular}

Ratio T.C.A. (mg./1.) : tri (p.p.m.) $=3.4: 1$.
The amounts for workmen dealing all day with tri confirmed the relation calculated above for the theoretical exposure.

The coefficient of determination, $B=0.46$, together with a study of the total amounts shown in Fig. 4 showed to what extent the wide scatter of the results might affect the relation we tried to establish between elimination of T.C.A. and exposure to tri.

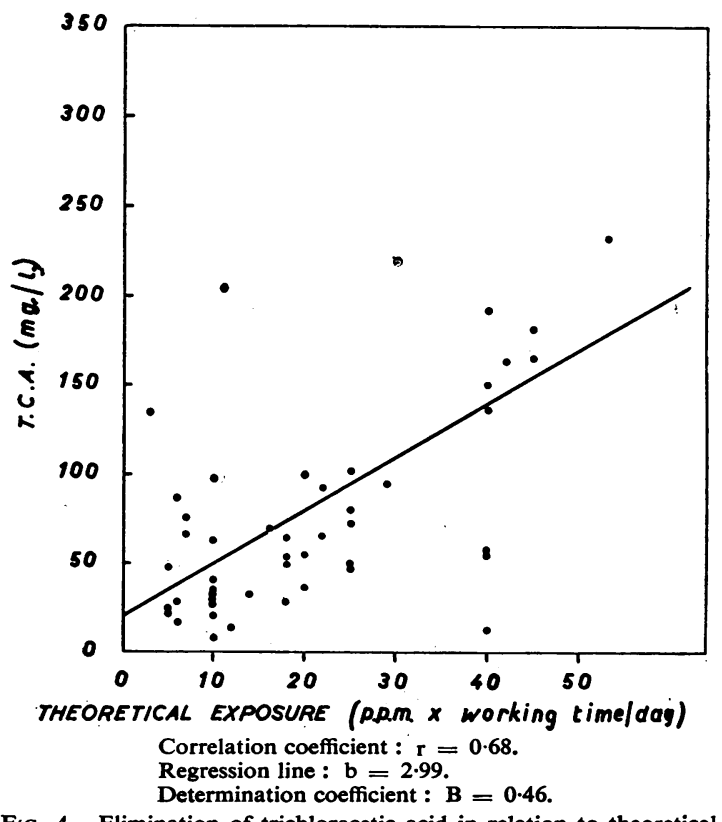

FiG. 4.-Elimination of trichloracetic acid in relation to theoretical exposure to trich'orethylene. 
The ratio of T.C.A. to theoretical exposure varied in fact between the extremes $20: 1$ and $1: 2$; the majority of cases, however, varied between $4: 1$ and $2: 1$. The main factors in this wide disparity were (1) individual variability regarding the breaking down of tri into T.C.A.; (2) lack of precision in considering the measurement of the concentration of tri in the air as a criterion of the exposure of the workman, seeing that the air analysed consisted merely of samples taken during working hours.

During our investigation we twice found cases of workmen whose exposure to tri did not exceed 20 to 30 p.p.m., but whose elimination of T.C.A. exceeded $200 \mathrm{mg}$./1. A thorough examination of working conditions revealed that these two men regularly cleaned the tri equipment, a job that exposed them periodically to very high concentrations of tri in the air. Another instructive example was the case of the man who spent only three to four hours per week cleaning the tri apparatus but whose elimination of T.C.A. amounted to 130 mg./1.

We tried to find if there was any relation between the elimination of T.C.A. and (1) the age of the workmen, (2) the duration of employment working with tri, or (3) the kind of apparatus used. With this in view we calculated the relation of T.C.A. to theoretical exposure for different age groups. The results appear in Fig. 5. We concluded that elimi-

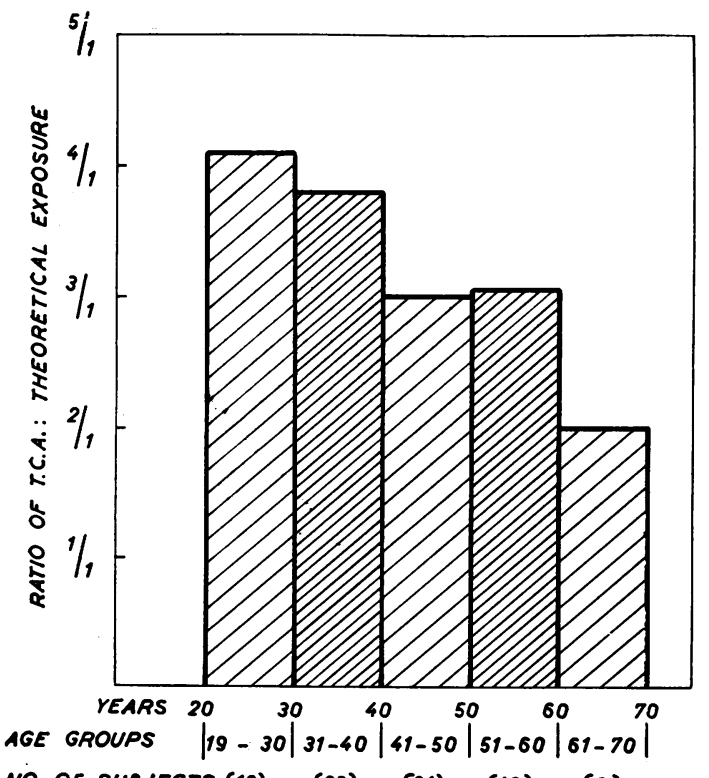

NO. OF SUBJECTS (12) (23) (21) (10) (6)

FIG. 5.-Elimination of trichloracetic acid in relation to theoretical exposure of men of different ages.

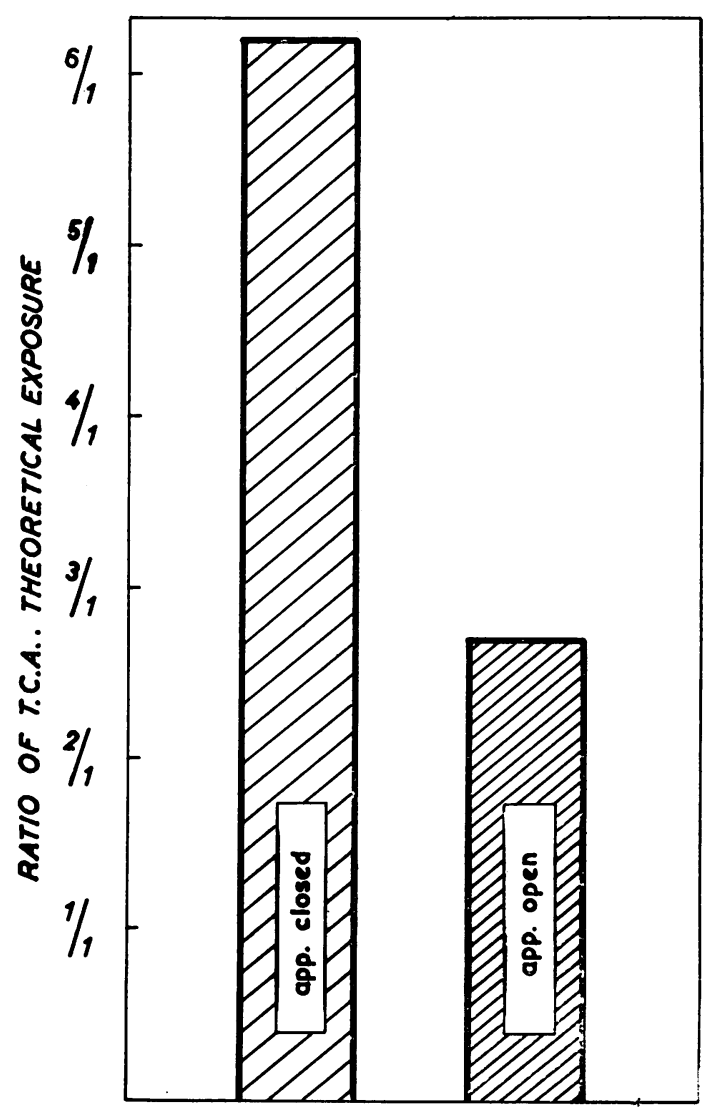

FIG. 6.-Elimination of trichloracetic acid in relation to theoretical exposures by workers dealing with closed and open apparatus.

nation of T.C.A. was distinctly greater in young men than in older men. There did not, however, seem to be much relation between the elimination of T.C.A. and the number of years spent working with tri.

Fig. 6 shows the average ratios of T.C.A. to theoretical exposure for both closed and open apparatus. We noted that elimination of T.C.A. in relation to theoretical exposure was very much higher for men working at closed apparatus than for men working at open apparatus. This difference is certainly due to the fact that the concentrations of tri found in the air in the region of the closed tanks are relatively low. Nevertheless, these men are occasionally exposed to very high concentrations of tri which evade air analyses, especially during the cleaning of the apparatus-a job that causes relatively high elimination of T.C.A.

We had the opportunity of studying variations in the elimination of T.C.A. by three men working 


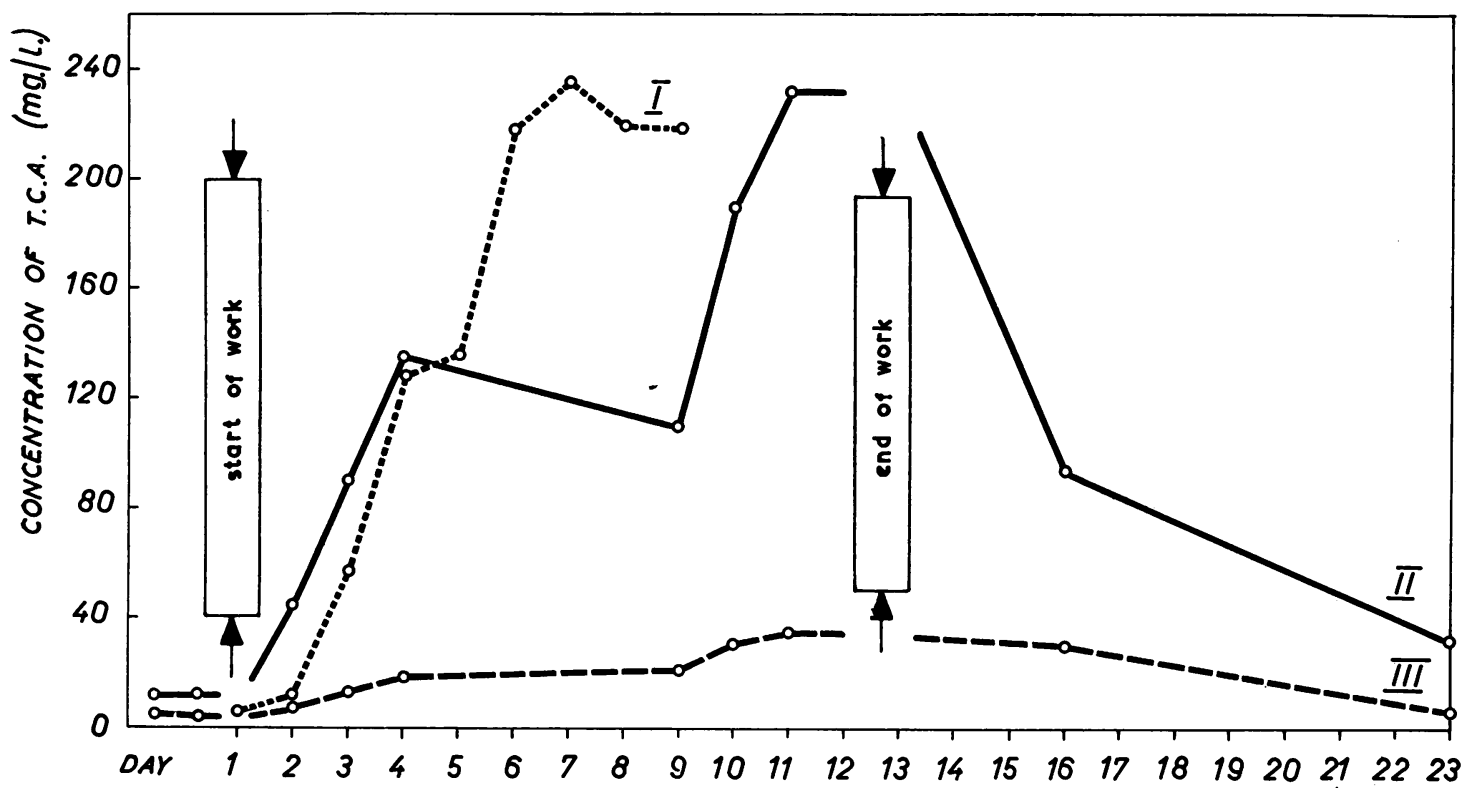

FIG. 7.-Variation in elimination of trichloracetic acid by men dealing with trichlorethylene for a fixed period.

near an open tank for a fixed period (Fig. 7). Concentration of tri in the air near the tank varied, in the case of workman No. I, from 6 to 84 p.p.m. (average 30.5 p.p.m.) and, for Nos. II and III, from 27 to 60 p.p.m. (average 35.6). For the first five to 10 days of exposure the elimination of T.C.A. in the urine increased. Three days and 10 days after exposure we still found considerable concentration of T.C.A. These results agree with observations made by Ahlmark and Forssman (1951b), by Nash and Sherwood (1953), and by Soucek, Theisinger, and Paveltrova (1952).

\section{Medical Examination of Men Working with Tri}

Case Histories.-The 50 persons $(49$ men and one woman) working with tri had an average age of 43 years at the time of the clinical examination. Differences of age are shown in Fig. 8.

The length of time these people were in contact with tri varied from one month to 15 years, the average being three and three-quarter years. The division into total periods of exposure is shown in Fig. 9.

In Fig. 10 we grouped together all subjective troubles. The workers themselves attributed most of their ailments to contact with tri. Complaints were sometimes made spontaneously, sometimes after questioning by the doctor. Of the 50 workers questioned, only two had no complaints; $66 \%$ complained of symptoms which, in our view, seemed characteristic of exposure to tri ; $38 \%$ had had to consult their doctor about these symptoms. It is probable that, as regards most of these symptoms, any other group taken from the same social level would have shown an incidence similar

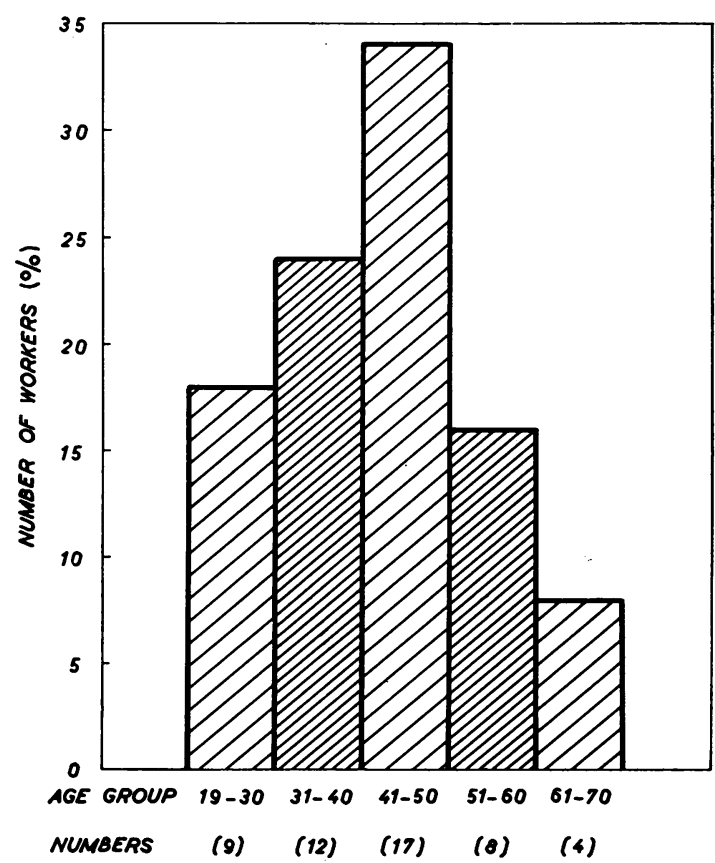

FiG. 8.-Age of workers examined. 


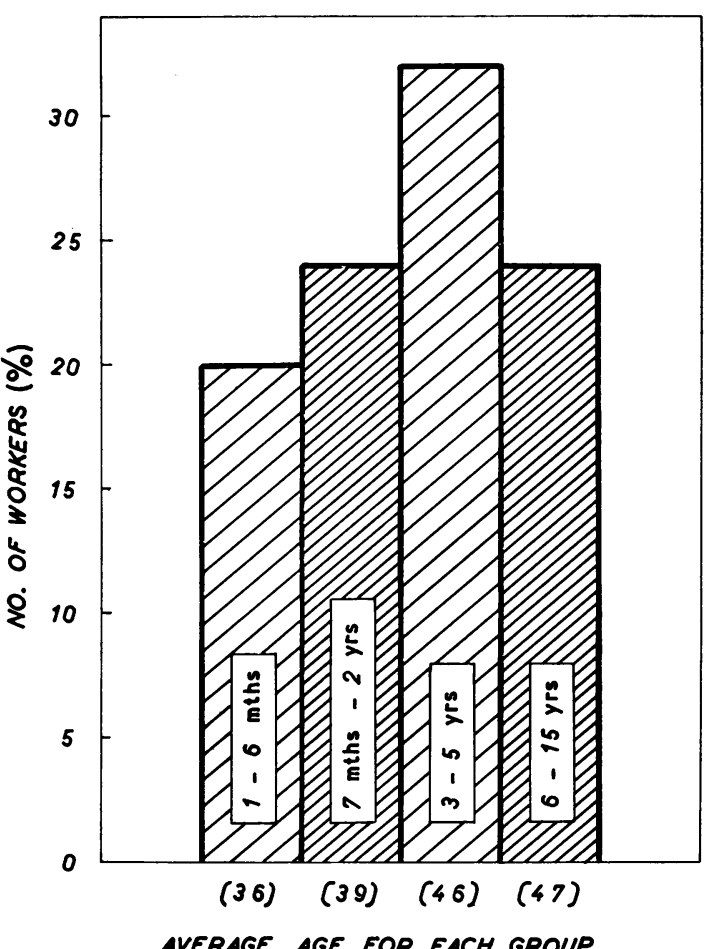

FIG. 9.-Duration of exposure to trichlorethylene of workers examined.

to that of Fig. 10. We hold, nevertheless, that the incidence of certain symptoms such as fatigue, dizziness, inability to tolerate alcohol, was particularly high in this group.

Examination of the Nervous System.-In this statistical study we distinguished between neurological changes, disorders of the vegetative nervous system, and psychical changes.

Among neurological changes we included any modification of vision, of the proprioceptive or cutaneous reflexes, of the corneal reflex, of cutaneous sensitivity, together with signs of slow tremors, of ataxia, or of nystagmus. If only those subjects showing several modifications or very pronounced symptoms are included we found neurological changes in $28 \%$ of our workers.

Disorders of the vegetative nervous system included excessive perspiration, circulatory symptoms, fine tremors, trembling eyelids, functional disorders of the gastro-intestinal system, palpita. tions, tachycardia, extrasystoles, praecordial pain, together with pronounced modifications of the dermographism. Confining ourselves to cases showing either several of the above symptoms in a mild form, or one serious symptom, we found disorders of the vegetative nervous system in $36 \%$ of our workers.

Diagnosis of psychical changes was based on the results of tests described above together with a clinical examination of the subjects. These examinations gave the following results :

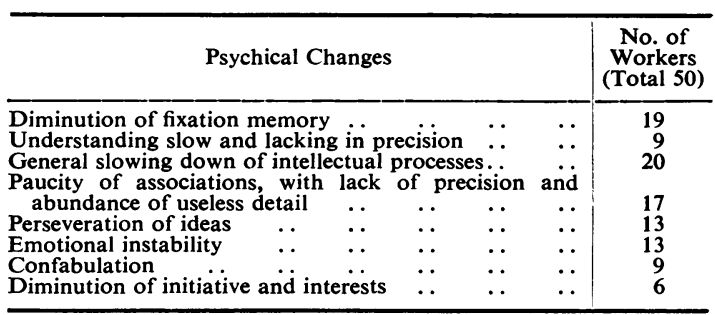

We noted that 17 workers (34\%) had a slight or moderate psycho-organic syndrome. In eight the psycho-organic syndrome was similar to that of persons suffering from alcoholic poisoning, arteriosclerosis, or of persons over 60 years of age. In nine cases, however, in the absence of any other possible aetiological factor, we diagnosed a psycho-organic syndrome caused by chronic exposure to tri.

Blood Tests.-Examination of the composition of the blood gave the following results :

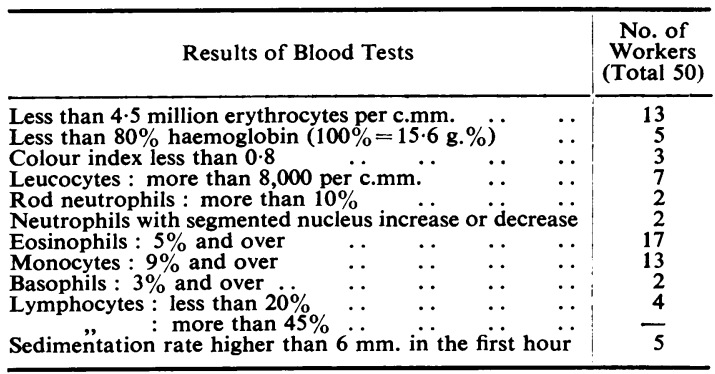

Biochemical Tests.-These tests gave the following results :

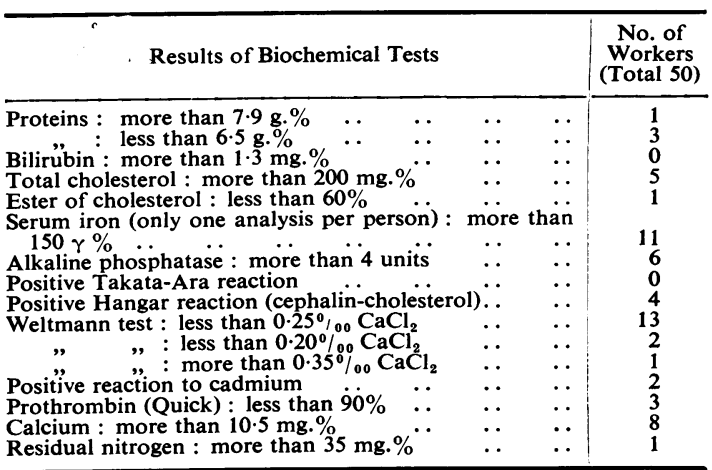


We must point out that most of the figures attained deviated only slightly from normal. We were unable to diagnose a single case of liver or kidney trouble with certainty. In $10 \%$ of the workers, however, modifications shown by the biochemical tests were sufficient to warrant a suspicion that the liver was slightly diseased or at least that its function was slightly impaired. We cannot, on the basis of these chemical tests, conclude that there is any causal relation between liver troubles and contact with tri.

Various Clinical Observations.--In the 50 workers we noted various other changes which may be classified as follows :

\begin{tabular}{|c|c|c|c|c|c|c|c|}
\hline \multicolumn{7}{|c|}{ Observations } & \multirow{2}{*}{$\begin{array}{c}\begin{array}{c}\text { No. of } \\
\text { Workers } \\
\text { (Total 50) }\end{array} \\
22 \\
9\end{array}$} \\
\hline \multicolumn{7}{|c|}{$\begin{array}{l}\text { Pharyngitis } \ldots \\
\text { Bronchitis, tracheitis, and emphysematous conditions } \ldots\end{array}$} & \\
\hline Chronic tonsillitis & $\ldots$ & .. & .. & .. & . & $\ldots$ & 9 \\
\hline Conjunctivitis & .. & . & . & . & .. & . & 3 \\
\hline Stomatitis .. & $\therefore$ & $\because$ & $\because$ & $\therefore$ & $\therefore$ & .. & 2 \\
\hline Periodontosis & . & . & .. & .. & .. & .. & 18 \\
\hline Dental prosthesis & $\cdots$ & . & .. & .. & . & .. & 21 \\
\hline Bad dentition & & . & & . & . & .. & 11 \\
\hline Body weight less $t$ & $\operatorname{an} 1$ & ight-1 & & .. & $\cdots$ & $\ddot{*}$ & 20 \\
\hline Eczema $\quad \cdots$ & $\ldots$ & $\ldots$ & .. & .. & .. & .. & 0 \\
\hline Dermatomycosis & .. & .. & .. & . & . & .. & 2 \\
\hline Heart troubles & $\ldots$ & $\ldots$ & & $\therefore$ & .. & .. & 5 \\
\hline Systolic arterial pr & essur & greater & tha & $150 \mathrm{r}$ &. $\mathrm{Hg}$ & & 8 \\
\hline Arteriosclerosis & . & $\ldots$ & .. & .. & .. & .. & 7 \\
\hline Enlarged liver & .. & .. & .. & . & .. & .. & 13 \\
\hline Excessive indulgen & ce in & lcohol & .. & $\cdots$ & $\cdots$ & $\cdots$ & 7 \\
\hline
\end{tabular}

General Remarks on State of Health.-Most of the workers who handle tri are in a low-paid category, their professional and social ambitions are almost non-existent, and their standard of living is certainly well below that of the average Swiss workman. We were not therefore surprised to find that the general health of the men examined was frequently bad.

As we were not acquainted with the normal incidence of disease in the various categories of Swiss workmen, we could not state with certainty to what extent subjective troubles and those revealed by clinical examinations might be attributed to contact with tri. It did seem to us, however, that troubles and lesions of the peripheral, central, and vegetative nervous systems were very frequent in this group. For this reason we endeavoured to establish a relation between the rate of incidence of both nervous troubles and subjective troubles and the known factors regarding exposure.

In Fig. 11 we classified workers according to their exposure to tri. We found that the rate of incidence of vegetative and neurological disorders was distinctly higher in Group III than in the other two groups. Results were submitted to statistical analysis using the Fisher (1946) $2 \times 2$ tables
SYMPTOMS

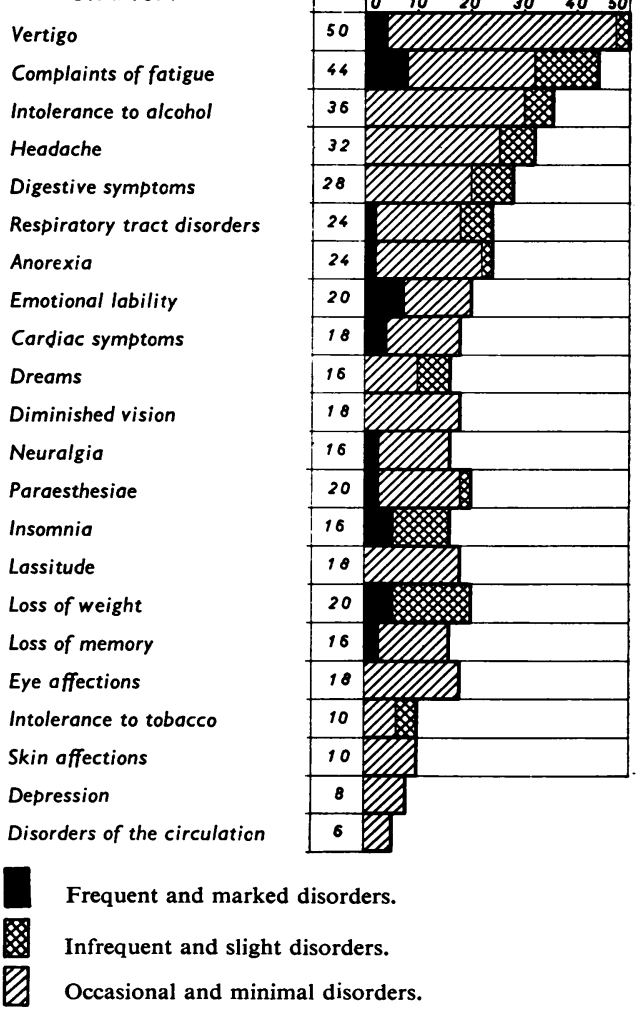

Fig. 10.-Subjective troubles of 50 workers dealing with trichlorethylene. The horizontal columns represent the rate of incidence of troubles as a percentage of the number of workers examined.

test. There were significant differences $(p=0.05)$ in the incidence of neurological disorder between Groups I and III, while between Groups II and III there were significant differences $(p=0.05)$ in vegetative and neurological disorders. Other differences were not significant.

Similarly, we classified our 50 workers in three categories according to the amount of T.C.A. eliminated in the urine. The results plotted in Fig. 12 show that subjective, vegetative, and neurological disorders were more frequent in Groups II and III than in Group I. Statistical analysis revealed the following significant differences $(p<0 \cdot 01)$ : subjective disorders between I and II ; vegetative disorders between I and II and between I and III ; neurological disorders between I and (II + III).

In Fig. 13 we divided workers into four categories according to the total length of time spent working with tri. Subjective symptoms were fairly equally divided between the four categories. We noticed, however, that vegetative, neurological, and psychical 


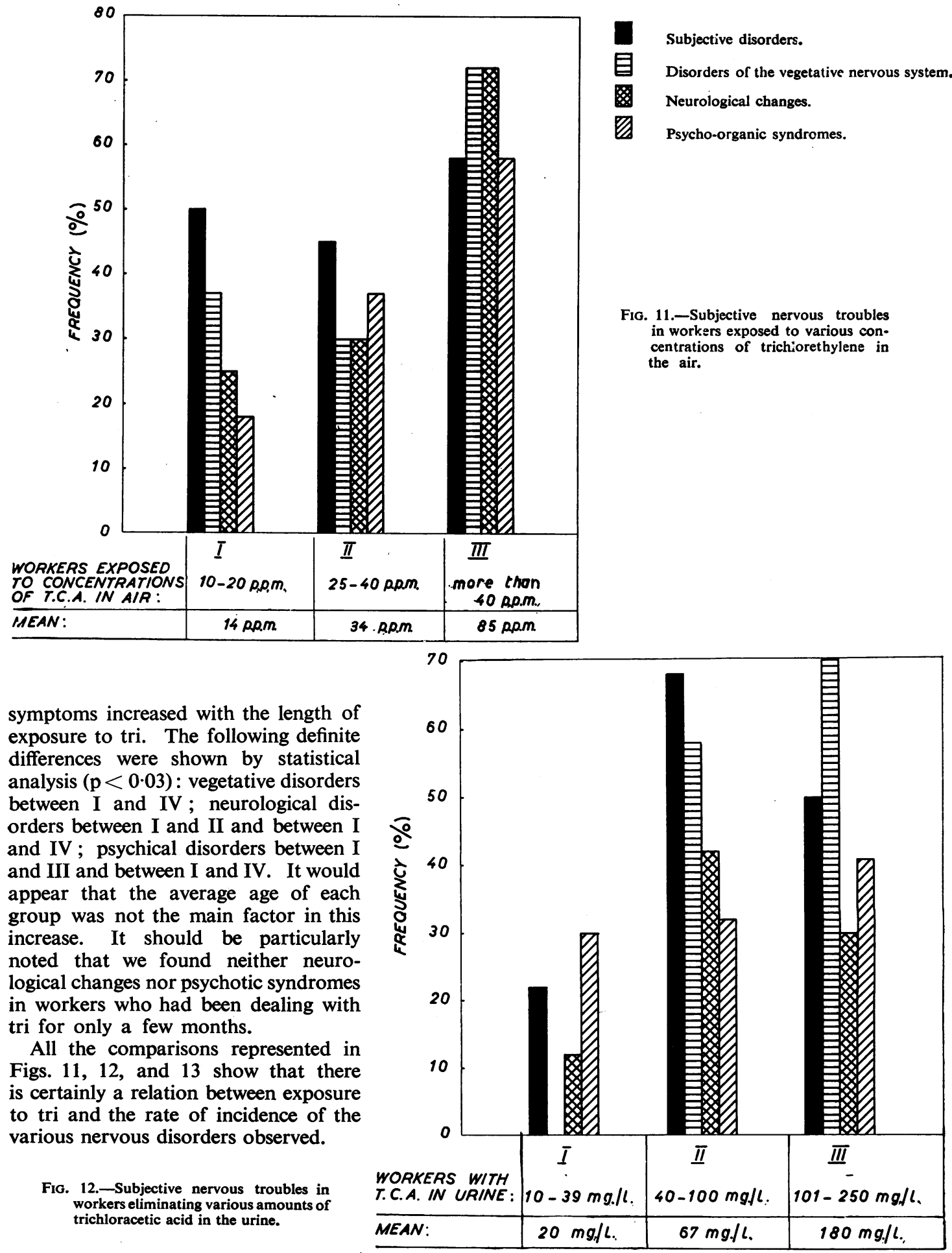




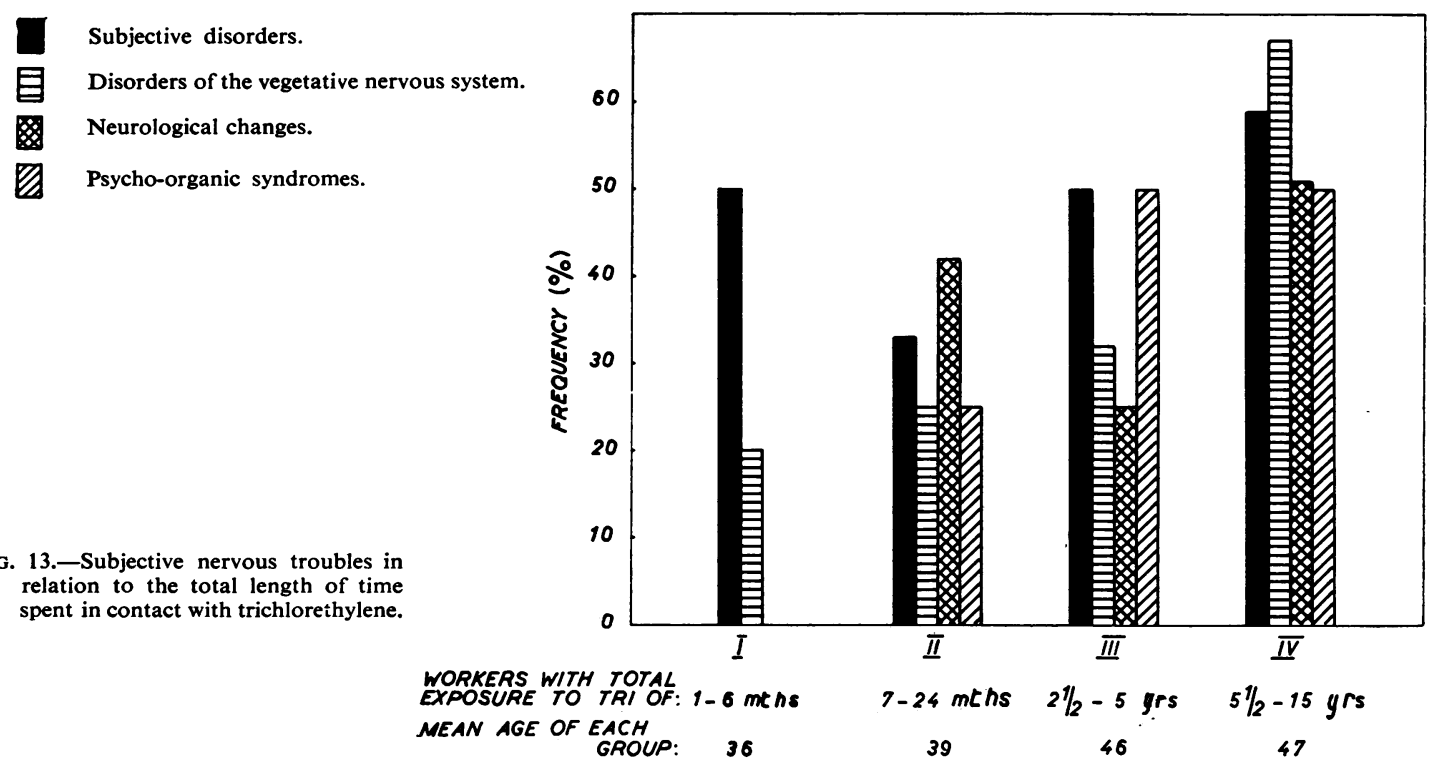

\section{Discussion of Results}

Our work showed that the determination of the concentration of tri in the air provided useful information regarding the efficacy of the tri plant in use and the dangers attendant on the methods of work. We had, however, to admit that often such readings provided insufficient indication of the total extent of exposure of the worker, who might sometimes inhale large quantities of tri which would not be included in the routine air analyses (special tank cleaning jobs, renewal of tri, etc.).

The simultaneous measurement of tri in the air and the amount of T.C.A. eliminated revealed the existence between these phenomena of a ratio corresponding, on an average, to the following : T.C.A. (mg. /1.) : tri (p.p.m.) $=3: 1$.

This ratio differed widely from one individual to the next, but in most cases it varied between $2: 1$ and $6: 1$. These ratios were valid in respect of continuous exposure for eight hours per day and for concentrations of tri in the air varying between 10 and 100 p.p.m.

Frant and Westendorp (1950) studied the relationship between elimination of T.C.A. (in mg./1.) and exposure to tri (in p.p.m.) in the case of seven workers and found proportions varying from $4: 1$ to $1: 1$. Friberg, Kylin, and Nyström (1953) found in the case of three workers exposed for five days to tri vapours of between 100 and 150 p.p.m. an elimination of T.C.A. varying between 250 and $500 \mathrm{mg}$. $/ 1$. These results were equivalent to a ratio of $2 \cdot 5: 1,3: 1$, and $6: 1$. These few 
from being a reliable guide. We consider that the determination of T.C.A. is, by itself, insufficient and should be accompanied by air analysis in order to arrive at the degree of exposure of the workers.

According to Ahlmark and Forssman (1951a), the limit of tolerance of T.C.A. should be fixed at $20 \mathrm{mg}$. $/ 1$. We may conclude from our experiments that this limit of $20 \mathrm{mg}$./1. should correspond to an exposure of 5 to 10 p.p.m. On the other hand, we find that the majority of authors and of organizations dealing with industrial hygiene put forward a maximum allowable concentration of 100 to 400 p.p.m., corresponding to an elimination of T.C.A. of at least $200 \mathrm{mg}$./1. There is, therefore, a considerable discrepancy between permissible limits for both tri in the air and T.C.A. in the urine. Russian and Czechoslovak authors are alone in laying down a limit of 9 p.p.m., which corresponds to the maximum concentration of T.C.A. put forward by Ahlmark and Forssman.

Our clinical examinations revealed that most of the workers suffered from various nervous troubles which increased with exposure to tri, from which we may conclude that some, at any rate, of the troubles observed should be attributed to contact with tri. Symptoms of chronic poisoning were caused by exposure to concentrations of tri in the air varying, in general, between 20 and 80 p.p.m. the average being about 40 p.p.m. The same workers eliminated quantities of T.C.A. varying in general between 10 and $250 \mathrm{mg}$./1., the average being $96 \mathrm{mg} . / 1$.

From these results we conclude that the maximum permissible concentration of tri in the air for continuous work should be fixed at less than 40 p.p.m., and the corresponding limit of T.C.A. in the urine at less than $96 \mathrm{mg}$. $/ 1$.

\section{Summary}

The concentrations of trichlorethylene (tri) vapours have been measured in the air of 24 workshops, and the eliminations of trichloracetic acid (T.C.A.) have been determined in the urine of 73 workers. A method based on the Fujiwara reaction was used.

The 96 air analyses gave values between 1 and 335 p.p.m., most of them lying between 20 and 40 p.p.m. The open trichlorethylene apparatus gave higher values (59 p.p.m.) than the closed ones (23 p.p.m.). A series of consecutive measurements during a period of three to four hours showed a great variation of the values due to the actual degree of ventilation and of utilization of the apparatus.

The concentration of trichloracetic acid varied between 8 and $444 \mathrm{mg}$./1. urine; the mean value was $84.7 \mathrm{mg} . / 1$.

The ratio between the elimination of trichloracetic acid in $\mathrm{mg}$./ 1 . and the trichlorethylene exposition in p.p.m. for the men occupied the whole day with trichlorethylene was, in the mean, equal to $3: 1$. This ratio varies greatly, the younger workers having on an average a ratio of $6: 1$ and the elderly subjects one of $2: 1$.

The eliminated trichloracetic acid is in the mean $13 \%$ of the trichlorethylene inhaled during a work period of eight hours.

The clinical examinations showed a relatively high frequency of subjective complaints, of alterations of the vegetative nervous system, and of neurological and psychiatric symptoms. There is a relationship between the frequency of those nervous alterations and the degree of exposure to trichlorethylene.

The determinations of the concentration of trichlorethylene in the air and the corresponding elimination of trichloracetic acid in the urine show that there is a great discrepancy between the actually accepted mean allowable concentration value for trichlorethylene and that for trichloracetic acid. We conclude from our results that the mean allowable concentration for trichlorethylene should be fixed below 40 p.p.m., and that the mean allowable concentration for trichloracetic acid should be fixed below $96 \mathrm{mg}$. $/ 1$.

\section{REFERENCES}

Ahlmark, A., and Forssman, S. (1951a). Arch. industr. Hyg., 3, 386. Bardodèj, Z., Berka, I., Chalupa, B., Nesvadba, O., and Vyskočil, J. (1952). Prakt. Lék., 4, 441 ; abstract Arch. industr. Hyg., 8 , 85 (1953).

Barrett, H. M., Cunningham, J. G., and Johnston, J. H. (1939). J. industr. Hyg., 21, 479.

Bleuler, E. (1943). Lehrbuch der Psychiatrie, 7th ed. rev. by M. Bleuler. Springer, Berlin.

(1954). Endokrinologische Psychiatrie. Thieme, Stuttgart.

Fabre, R. (1949). Proc. 9th int. Congr. industr. Med., London, 1948, pp. 546-550. Wright, Bristol. Fisher, R. A. A. (1946). Statistical Methods for Research Workers,
10th ed. Oliver and Boyd, Edinburgh and London.

Forssman, S., and Holmquist, C. E. (1953). Acta pharmacol., Kbh., 9, 235.

Frant, R., and Westendorp, J. (1950). Arch. industr. Hyg., 1, 308. Friberg, L., Kylin, B., and Nyström, A. (1953). Acta pharmacol., Kbh.,

Knoepfel, A. (1952). Nervenarzt, 23, 55.

Nash, P. H., and Sherwood, R. J. (1953). British Journal of Industrial Medicine, 10, 202.

Soucek, B., Theisinger, J., and Paveltrova, E. (1952). Prakt. Lék.,

4, 31 ; Abstract Arch. industr. Hyg.; 6, 461.
Truhaut, R. (1951). Ann. pharm. franc., 9, 175. 